\title{
Understanding Risk and Uncertainty in Project Management
}

\author{
Mundhir AL Hasani, PhD Candidate
}

Bond University, Faculty of Society \& Design, Queensland, Australia

Doi: 10.19044/elp.v5no1a3 $\quad$ URL:http://dx.doi.org/10.19044/elp.v5no1a3

\begin{abstract}
This paper seeks to discuss different aspects of risk and uncertainty. This paper will then look at the historical presentation and understanding of the two concepts and how different experts contributed, in the course of time, in understanding the two concepts. Other sections of the paper will look at the different ways that are applicable in reducing the harmful effects of risks and uncertainty. As will be presented, resources must be set aside to deal with risk and uncertainty. The paper will demonstrate that historically, the understanding of both risk and uncertainty has been a number of changes through while previous knowledge and information has been improved with a view to enlightening society on the best ways to manage their adverse effects. However, during the entire discourse, it is clear that risks can be tabulated and quantified with a view to reducing their harmful effects while uncertainty is unforeseen and cannot be predetermined.
\end{abstract}

Keywords: Risk, uncertainty, probability, project, project management.

\section{Introduction}

Cognisant of the various challenges that could portend in life about risk and uncertainty, many scholars and general societies have been faced with risk and uncertainties in all aspects of life. This has called for various strategies aimed at understanding the concept of risks and uncertainties and the issue has been debated since time in immemorial. This paper will affirm that both risks and uncertainty have faced humanity for a long time. Risk refers to both negative and positive outcomes that can be calculated through probabilities and historical occurrences while uncertainties are unforeseen negative or positive eventualities that cannot be determined at present.

\section{Historical Overview}

The concepts of risk and uncertainties have been the subject of discussion in various fields and academic discourse for a very long time. 
Moreover, each and every aspect of human life and engagement faces risks and uncertainties, and this means that judgement decisions must be made at all times. This section gives a historical presentation of the concept of risk and uncertainties and, evidently, states that different people across disciplines contribute immensely to the understanding of the contemporary concepts of risks and uncertainties. In retrospect, it is important to acknowledge that the understanding and comprehension of the subject matter have undergone different inputs and interpretation, thus making improvements in the course of time.

According to Goodhart (2009) in Greece, the first recorded attempts in risk analysis and regulations took place in Phoenicia. In this respect, there were different institutions that were put in place to counter risks and prize trade within the maritime frontier. Wealthy business people gave letters indicating awards on credits and how profits would be shared. Similarly, indication on different indemnities that would be awarded to people was also introduced.

In 100BC, greater innovations took place to safeguard against imminent risks, and this was evident in the manner in which ships and other equipment were made. Navigation at sea was also improved, just as was the development of financial securities. Development of mathematics as a discipline also took place during the same period. Future predictions through celestial mappings were also enhanced.

According to Ivanov (2003), the renaissance that took place in the 1500 s supported the development of science. Risks became vital in price formulations and potential profits that would be earned. Capitalism gained popularity and with it came things like bookkeeping and forecasts; current accounting was born as a result. Understanding the calculation of margins, profits and percentages took place.

Capitalism called for a more advanced approach in forecasting and predictions and this enabled scientist to devise a means of predicting future events. The Chinese came up with algebra that proved useful to that end. Italy witnessed the first set of banks that established up in Genoa and Venice.

Between 1445 and 1490, Paccioli introduced the concept of gambling: gaming and chance. In the analysis, it became clear that there was a likelihood of exploring the chance of a future event taking place. In those times, a metaphysical analysis was taken by event since the advent of qualitative analysis to give explanations on natural occurrences. Gambling took shape; the outcome of events meant that the probability of events relied upon favourable and unfavourable occurrences. Cardona and other like-minded people took advantage of that understanding and developed concepts of using dice and other gaming tools (Pushkarskaya et al., 2015; Walker et al., 2017). 
Gigerenzer (2005) argues that in the mid- $17^{\text {th }}$ century, Blaise Pascal invented what became the first calculator. On the same note, the present day decision making theory formed root. That was essential in helping make numerous decisions in case of uncertainties. The scientists also introduced statistical inference that was essential in hypothesis development in the case of the sampling. Fermat borrowed a leaf from previous works and formulated foundations of the present day probability theory. Economics and mathematics were the first disciplines to appreciate those findings and used them in their analysis.

Jacob Bernoulli, who lived between 1655 and 1705, introduced large number laws and introduced the error term, confidence level and means of improving accuracy in data and analysis. The broad name given to those discoveries were utility hypothesis and have enormous applications in various disciplines today.

The fundamental difference between risks and uncertainties were first drawn by Bayes (Skinns, 2011). It became clear that uncertainties were linked to environmental factors. They were unknown and unpredictable. Bayes ideologies were enhanced by Francis Galton, who advanced the concept of regression and correlation. The concepts were an important milestone in calculation and prediction of risks and uncertainties.

Uncertainty and risk are considered to be multidisciplinary and multifunctional concepts, which are useful in different areas such as accounting, marketing operations, finance, organisational design and human resource management. In fact, risk and uncertainty are crucial to make sure that every project succeeds. In addition to that, these concepts borrow ideas from engineering, human behaviour, mathematics, psychology and sociology (Smithson, 2015; Song et al., 2017).

Above discussed, contributions have undergone numerous revisions. To date, numerous scholars and academicians are still in pursuit of further improvements of concepts that can ease the understanding of risks and uncertainties. Over the course of development of the concepts, it is clear that risks can be calculated and determined while uncertainties are beyond prediction and human control.

\section{Risk}

In order to understand risk, let's define a project as an attempt in which physical, human and financial resources are utilized in order to accomplish a goal of specific tasks, within a certain limitation of time and cost. The major aim of accomplishing a project is to bring about a constructive change by delivering quantitative and qualitative objectives (Elfaki et al., 2014; Koleczko, 2012; Serrador \& Turner, 2015; Papke-Shields \& Boyer-Wright, 2017). Nowadays, risk management practices are required in order to get 
positive outcomes from a project. These risk amendment practices help in the achievement of economically effective objectives and long-lasting future benefits. In addition to making a project successful, conduction of an effective risks analysis assists in the identification of certain risks which have the ability to alter the outcome as compared to expected and projected results (Nasirzadeh et al., 2016). In this way, previous practices can predict the occurrence of a risk. However, uncertainty cannot be projected in this manner.

According to Rutherford (2002, p. 182), "Risk is an outcome which can be calculated through measuring probabilities." In project management, risk refers to the measurement of both the probability and consequence of failing to achieve a set goal of the project. Most professionals accept the fact that risk can be equated with uncertainty. However, when taking risk into consideration, it is necessary to ensure that the consequence that is related to the event must be accounted for. Assessing risk is complex and dynamic over time as both the probability and consequence of the occurrence are not measurable parameters; thus there is a need to use estimation based on judgement or statistics and in some cases the application of other procedures. In general, once consequence or probability shows an increase, a possible increase in risk is also expected (Chandra, 2015). It is very important to take into consideration probability and consequence in risk management.

In order to comprehend the significance of risk, there is a need for a deeper investigation into the true meaning of project management. Project management has to overcome numerous obstacles while accomplishing anticipated outcomes through a process of preparing, organising, acquiring, and handling certain resources. Most importantly, the challenge that project management has to overcome includes achievement of all set goals and objectives whilst considering the set constraints including range, time, requirement, quality and budget problems, being measured and organized by a project manager (Babatunde \& Perera, 2017). In order to achieve this, two steps are required. Firstly, the project management team should adopt a practical risk management methodology which is efficient enough to detect risks at early stages, and thus can predict how far those risks can arise or certain opportunities can emerge. Secondly, it should adopt a portfolio method which manages risks in integrated and cost effective ways, throughout the entire event and portfolio of project. If both of these methodologies are adopted, then effective and sound decision making can be made which will eventually make the management strong and fast enough to take active steps during periods of change and uncertainty. In other words, the significance of risks for project management can be well understood in making effective cost budget, accomplishing the goal of earning profits, gaining success or not being an enterprise, and getting an authoritative and trustworthy image in eyes of their key stakeholders (Babatunde \& Perera, 2017). 
Regarding project management, all profitable and professional activities are actually risks in the future. So, in order to recognize the probability of risk, both science and judgement needs to be considered. Probability theory refers to a branch in mathematics that is focused on analysing random phenomena (Bernstein, 1998). The result of a random event may not be known before it happens, but possible outcomes can be known. The probability is of two types, either when the object itself is really uncertain, and is determined by chance; or when, although to be sure of an object already (Keynes, 1921). Humans may use probabilities on all aspects of their lives. Taking into account the risk of any event, the assessment of all possible outcomes is usually weighted through its probability of occurrence. Indeed, judgement and science can be utilised in measuring risk where probability of occurrence and impact are weighted, and decisions largely depend on placement of mechanisms for controlling and managing risk. Making sure that risk does not become uncontrollable by risk management, expected utility theory was created to better understand and analyse attitudes toward risk, such as risk seeking and risk aversion, particularly when it is applied to decision making. It is important to note that theoretical constructs applicable to risk have been examined for more than a century to come up with a better understanding of its impact and usefulness in practical application (Bernstein, 1998).

\section{Probability}

Probability theory is known to be very useful in forecasting, yet the quality of information that is the foundation of probability estimates might dictate the accuracy and quality of expected outcomes. Probability depends on historical event observations to come up with future events (Bloom, 2014). Indeed, it is a complicated task to come up with decisions for future occurrences in conditions of uncertainty. Probability is a technique which is mainly used to evaluate quantitative risk. Regarding project management, the outcomes of any quantitative risk analysis is employed for numerous purposes (De Oliveira et al., 2017; Dziadosz \& Rejment, 2015). For example, the results are used to rank risks according to their gravity and rate of occurrence. At the end of each project stage, deduced probabilistic cost and schedule approximation for set milestones assist the project managers in allocating resources effectively. Moreover, the results help in evaluating probability of meeting set cost margin, technical performance, set goals, achieving, and authenticating established technical performance measures. Considering these effects of outcomes of quantitative risk analysis, it is highly important to get precise outcomes. This can be done in two ways, firstly, by development of an authentic model structure, and secondly, by integrating exact probability data. 
As for project risk management, Koleczko (2012) pointed out that there is a lack of attention afforded to these factors, which might result in inaccurate outcomes. Therefore, it is necessary that the model be designed carefully and validated before its application in the decision making process. Take note that once the outcome is not represented by one or more point values, probability distributions should be a suitable choice. The quantitative stochastic analytical approach refers to a methodology that combines a model structure and probability distributions. This can be used in risk management wherein it is expected to create a series of probability distributions for potential risks.

Keynes (1921), evaluated probability in his theory in which he basically analysed the effect of periodic information on the effectiveness of investment-based decision making. He also investigated that investors cannot be the rational actors of classical theory. This owes to the impossibility of getting cold calculation from projected outcomes. He also detected certain events in which it is impossible to make scientific calculations for computing probability. The study also revealed that there exist high instability of the facts and data which are used to evaluate future revenues and outcomes for investors. In short, there exists insignificant and slight information of the factors governing future investment yield (Koleczko, 2012; Papke-Shields \& Boyer-Wright, 2017). However, Bayesian's methodology used probability retrieved from older data which was revised using new factual information. In other words, newer probabilities are statistically compared with previous ones (Bernstein, 1998). According to Jacob Bernoulli (1738), a risk can be better managed if three requirements are assumed which includes complete information, independent trials and significance of quantitative assessment. These suppositions are highly important in finding out how effectively these measurements and data can be used to compose and forecast future decisions (Bernstein, 1998).

\section{Uncertainty}

According to Rutherford (2002, p.182), "Uncertainty concerns the unknown future". Uncertainty is part of project management wherein assumptions and expectations are involved in analysing the project's outcome. According to Knight (1921), there are two different types of uncertainty. The first is called measurable probability which the author labelled as "risk." The second is termed unquantifiable ambiguity or uncertainty. When applied to project management, risk can be given a probability value while uncertainty will be immeasurable. This distinction is deemed necessary as risk is concerned with objective probabilities while uncertainty might require taking into account subjective probabilities (Rutherford, 1995). Because uncertainty is considered to be a condition of insufficient knowledge, it can be affected by 
uncertainty. Attitudes toward risk might be useful in understanding the decision making process under uncertainty, although this method may fail to consider human response to uncertainty. Moreover, risk can be measured, and results can be estimated, and a contingent style of management can be used to manage the inaccuracy of forecasting.

There are typically three traditional views of human responses to uncertainty. These are used to underpin most psychological approaches (Koleczko, 2012; Smithson, 2015).

1. The knowledge seeker;

2. The certainty maximiser; and

3. The intuitive statistician-economist.

Let's take a look at how individuals manage in the existing unreliable world. Regarding this, generally three uncertainty paradigms exists which must be analysed here. These include probability, delay and lack of clarity. Here, there is a need to establish a link between uncertainty and emotion. This is evident from Keynes' literature that mainly assessed the variances in orientation to lack of knowledge and uncertainty. Moreover, another study highlighted the significance of choices made upon proper reasoning which allows people to produce, realize, and validate their decisions (Tversky \& Kahneman, 1981).

The first view is that of knowledge seeker which rarely exists in project management. It basically supports those people who are looking forward toward gathering new facts and skills despite short-term uncertainty and ignorance; communicate openly; and does not justify previous philosophies solely. This is rather an idealistic approach in which individuals rely on existing data for forecasting outcomes. This is so because both process and results appear too great an investment. As mentioned previously, most project managers feel restricted toward using their best judgements in making decisions regarding uncertainty. Project managers have many factors to take into account before they make an informal decision.

The second view is the certainty maximiser which highlights the devastating penalties of uncertainty, unpredictability and uncontrollability which affect the sentimental, rational and functional abilities of a decision maker (Meng \& Boyd, 2017). Other studies reveal that uncertainty is an equivalent of anxiety. Thus, individuals are inspired to minimize uncertainty (Karimiazari et al., 2011; Oliva, 2016). This idea is comparable to Keynes' view of animal spirits which assesses if decision makers feel an urge to take action against uncertainty in order to minimize the subsequent emotional state of anxiety. He stated that instead of mathematical probability, most of our positive doings are dependent on impulsive positivity. In short, the majority of our positive acts and long-term judgements are an outcome of these animal 
spirits. These are not resultant of weighted average, which is a product of quantitative benefits and quantitative probabilities (Koleczko, 2012).

The third is the view of intuitive statistician-economist. It initiates from observation and cognitive psychology and psychophysics. This view basically incorporates several models of cognition which are used to process data and information. It mainly signifies similar reactions of project management in risk matters and situations. "The dominate normative viewpoints, which have a lot in common with neo-classical economics, are probability theory and a view that humans as hedonic rent seekers, or in the case of project management, focussed solely on seeking profit and avoiding loss" (Bammer \& Smithson, 2008, p. 173). Now, sensible decision-makers select certain preferences, rank them according to expected outcomes, and enumerate them into utilities i.e. net benefits/costs. This process of maximising subjective expected utility then goes on by adding the probabilities and utilities. Next, the average of added results is calculated. The product final value for which utility is expected to yield highest value is then selected. Even though these elaborate models seem limiting, still most studies have concentrated on judgemental and decisional inaccuracies (Tversky \& Kahneman, 1982; Tversky \& Fox, 1995a, b).

According to Keynes (1921) and Knight (1921), risk can be quantified with the use of probability theory while uncertainty remains incalculable. This notion has been examined for many years, particularly the theoretical constructs of risk, as a way of better understanding its impact on practical application. This is the reason why different strategies, research and theories have been proposed to apply to risk analysis. In particular, probability is the most widely used method in project management for quantitative risk analyses. Probability is also considered to be a useful instrument for forecasting as the quality of information needed for probability estimates will be the basis for accuracy and quality.

Lastly, let's throw light on dissimilarity between risk and uncertainty. On one hand, precise probabilities are assigned under risks. Whereas, on the other hand, the concept of uncertainty states that one cannot assign precise probabilities. This results into allowing the decision makers to make judgements using existing knowledge, perception, information and characteristics of the project, and their relative approaches and opinions. This idea is supported by Tversky and Kahneman, and is quite evident from their studies. Their studies reveal that individuals do not appear as if they were value-maximisers. Instead, claim that they actually are! This is held true based on various rational philosophies. Thus, people play the role of problemsolvers. They make choices based on their perceptions, and consequently solve critical issues by carefully balancing and compromising between set goals and desired values. In other words, they are not inspired, but themselves create 
preferences by processing and choosing based on their own will and judgements (Koleczko, 2012).

\section{Conclusion}

In conclusion, risk and uncertainty differ because with risk, specific probabilities are assigned while with uncertainty, one cannot use specific probabilities. This may lead to the decision makers' need to make sound judgement based on available information, instinct, their knowledge of a particular project and their own attitudes and beliefs. Thus, decision-making under conditions of risk where assignments of estimated probabilities are applicable will allow the development of management strategies that will respond to it, such as monitoring and managing risk mitigation as a way of controlling the risk to the desired level. On the other hand, uncertainty is considered immeasurable. In order to manage risks, the first step starts with the management of uncertainty. Risk management relies on assessing and making choices so that the right ones may be prioritized. Once that has taken place, the management should make use of all the available resources to reduce the likelihood of the occurrences. Control implies looking at the probability of the negative occurrences and reducing them. Examples of risks arising from various things like financial markets, projects and programs. It is also evident that the higher the risk, the higher the return. Risk and uncertainties are eventualities that must be catered for during planning

\section{References}

Babatunde, S. O., \& Perera, S. (2017). Analysis of traffic revenue risk factors in BOT road projects in developing countries. Transport Policy, 56(7), 41-49. Bammer, G., \& Smithson, M. (2008). Uncertainty and Risk Multidisciplinary Perspectives. London: Earthscan.

Bernoulli, D. (1738). Specimen Theoriae Novae de Mensura Sortis. Commentarii academiae scientiarum imperialis Petropolitanae, 5, 175-192.

Bernstein, p. L. (1998). Against the Gods. Good approach to understanding the development and science of probability theory, risk and risk management. New York: John Wiley \& Sons.

Bloom, N. (2014). Fluctuations in uncertainty. The Journal of Economic Perspectives, 28(2), 153-175.

Chandra, H. P. (2015). Structural equation model for investigating risk factors affecting project success in Surabaya. Procedia Engineering, 125(3), 53-59. De Oliveira, U. R., Marins, F. A. S., Rocha, H. M., \& Salomon, V. A. P. (2017). The ISO 31000 standard in supply chain risk management. Journal of Cleaner Production, 151, 616-633. 
Dziadosz, A., \& Rejment, M. (2015). Risk analysis in construction project Chosen Methods. Procedia Engineering, 122, 258-265.

Elfaki, A. O., Alatawi, S., \& Abushandi, E. (2014). Using intelligent techniques in construction project cost estimation: 10-Year Survey. Advances in Civil Engineering, 2014, 11. doi: http://dx.doi.org/10.1155/2014/107926

Gigerenzer, G. (2005). Calculated risks: how to know when numbers deceive you. New York: Simon \& Schuster.

Goodhart, C. A. (2009). Money, information, and uncertainty (2nd ed.). Cambridge, Mass: MIT Press.

Ivanov, L. D. (2003). Reliability based renewal criteria for risk based inspection: Phase A: "level of confidence": definition, calculation and use for new designs and aging vessels. Houston, TX: American Bureau of Shipping. Karimiazari, A., Mousavi, N., Mousavi, S. F., \& Hosseini, S. (2011). Risk assessment model selection in construction industry. Expert Systems with Applications, 38(8), 9105-9111.

Keynes, J.M. (1921). A treatise on probability. London: Macmillan and Company.

Knight, F, H. (1921). Risk, uncertainty and profit. New York, USA: Dover Publication.

Koleczko, K. (2012). Risk and uncertainty in project management and decision making. Public Infrastructure Bulletin, 8 (1), 76-82

Meng, X., \& Boyd, P. (2017). The role of the project manager in relationship management. International Journal of Project Management, 35(5), 717-728.

Nasirzadeh, F., Mazandaranizadeh, H., \& Rouhparvar, M. (2016). Quantitative risk allocation in construction projects using cooperativebargaining game theory. International Journal of Civil Engineering, 14(3), 161-170.

Oliva, F. L. (2016). A maturity model for enterprise risk management. International Journal of Production Economics, 173, 66-79.

Papke-Shields, K. E., \& Boyer-Wright, K. M. (2017). Strategic planning characteristics applied to project management. International Journal of Project Management, 35(2), 169-179.

Pushkarskaya, H., Tolin, D., Ruderman, L., Kirshenbaum, A., Kelly, J. M., Pittenger, C., \& Levy, I. (2015). Decision-making under uncertainty in obsessive-compulsive disorder. Journal of Psychiatric Research, 69, 166173.

Rutherford, D. (1995). Economics- key concepts. London: Routledge.

Rutherford, D. (2002). Routledge dictionary of economics ( $2^{\text {nd }}$ ed.). London: Routledge.

Serrador, P., \& Turner, R. (2015). The relationship between project success and project efficiency. Project Management Journal, 46(1), 30-39.

Skinns, L. (2011). Risk. Cambridge, UK: Cambridge University Press. 
Smithson, M. (2015). Probability judgments under ambiguity and conflict. Frontiers in Psychology, 6, 674.

Song, Y. I., Lee, D. H., Lee, Y.-G., \& Chung, Y. C. (2017). Managing uncertainty and ambiguity in frontier R \& D projects: A Korean case study. Journal of Engineering and Technology Management, 24(3), 231-250.

Tversky, A \& Fox, C.R. (1995a). Ambiguity aversion and comparative ignorance. Quarterly Economic Journal.

Tversky, A., \& Fox, C. R. (1995b). Weighing risk and uncertainty. Psychological Review, 102(2), 269.

Tversky, A., \& Kahneman, D. (1981). The framing of decisions and the psychology of choice. Science, 211(4481), 453-458.

Tversky, A., \& Kahneman, D. (1992). Advances in prospect theory: Cumulative representation of uncertainty. Journal of Risk and Uncertainty, 5(4), 297-323.

Walker, D. H. T., Davis, P. R., \& Stevenson, A. (2017). Coping with uncertainty and ambiguity through team collaboration in infrastructure projects. International Journal of Project Management, 35(2), 180-190. 